\title{
A MEDIAÇÃO DE CONFLITOS O NOVO AMBIENTE PARA A JURISDIÇÃO: A ECO-JURISDIÇÃO COMPARTILHADA
}

\author{
Thaise Nara Graziottin Costa ${ }^{1}$ \\ Lídia Maria Ribas ${ }^{2}$
}

\begin{abstract}
RESUMO: O artigo tem o objetivo estudar a mediação judicial e a nova jurisdição que se instaura após a implementação das Leis $n^{\circ} 13.105$ e 13.140/2015. Objetivos da pesquisa direcionar o estudo ao novo modelo de jurisdição compartilhada, em um ambiente inovador da Eco-jurisdição ultrapassa-se as barreiras da litigiosidade para assumir a jurisdição compartilhada, participativa e humanizada. Utiliza-se para tal, a pesquisa bibliográfica, o método hipotético-dedutivo e as práticas metodológicas das autoras nos grupos de pesquisa que participam.
\end{abstract}

Palavras-chave: Mediação; Jurisdição; Compartilhada; Eco-jurisdição; Consenso.

\section{MEDIATION OF CONFLICTS THE NEW ENVIRONMENT FOR JURISDICTION: THE ECHO-JURISDICTION SHARED}

\begin{abstract}
The article aims to study the judicial mediation and the new jurisdiction that is established after the implementation of Laws 13.105 and 13.140 / 2015. Objectives of the research targeting the study to the new model of shared jurisdiction in an innovative Ecojurisdiction environment overcomes the barriers of litigation to assume shared, participatory and humanized jurisdiction. Bibliographic research, the hypothetical-deductive method and the methodological practices of the authors in the research groups that participate are used for this purpose.
\end{abstract}

Keywords: Mediation; Jurisdiction; Shared; Eco-jurisdiction; Consensus.

\footnotetext{
${ }^{1}$ Doutora em Direito pela Universidade Estácio de Sá do Rio de Janeiro (UNESA RJ), Estágio Doutoral Universidade de Coimbra, Portugal, Mestre em Direito UFP. Advogada, Mediadora e Professora do CJUD-RS

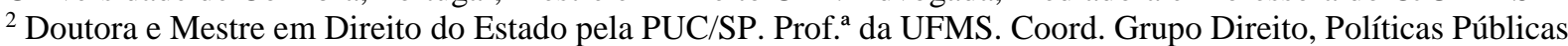
e Des. Sustentável e Tutela Jurídica das Empresas do CNPq.
} 


\section{INTRODUÇÃO}

A mediação de conflitos é uma modalidade de resolução de conflitos milenar, inclusive aplicada por tribos indígenas para decidir seus impasses e tomar decisões adequadas, tal método autocompositivo, assim foi implementado nos tribunais de justiça do país a fim de enfrentar as dificuldades sociais do século XXI, pois a jurisdição Estatal positivada está intimamente ligada à crise do Estado Democrático de Direito e à sua possibilidade efetiva de resolução de conflitos por meio de técnicas não-adversariais.

O acesso à justiça não se resume apenas à possibilidade de se submeter o conflito, por meio do processo é muito mais, é proporcionar ao cidadão que procure a tutela do Estado um ambiente adequado, uma justiça satisfativa e humanizada. Assim, a justiça deve trocar as lentes da litigiosidade e dar abertura para os meios autocompositivos, incentivando-os nas escolhas dos indivíduos pelo caminho mais condizente para a resolução de seus conflitos.

Este artigo tem o intuito de fazer uma pequena reflexão inovadora da tese doutoral realizada em Banca de defesa em 2017, com o objetivo de demostrar nesta pesquisa que no ambiente da mediação apresenta-se um novo modelo de jurisdição judicial e, por isso, a prestação jurisdicional do Estado-Juiz sofreu alterações, que denominamos de Jurisdição Compartilhada, num ambiente inovador da nova casa da jurisdição, a Eco-jurisdição contemporânea, saindo do modelo de jurisdição tradicional denominada voluntária e contenciosa para uma nova jurisdição compartilhada, participativa, humanizada e dialogada.

Após as Leis 13.105/2015 e 13.140/2015 que implementaram as Políticas Públicas de inclusão judicial dos meios autocompositivos, em especial a mediação de conflitos como forma adequada, rápida e eficaz no caminho da pacificação social dos conflitos, com a humanização da Justiça, o cooperativismo, o consenso e o diálogo.

Sabe-se que a atividade jurisdicional é aberta e complexa, pois o juiz em suas atribuições jurisdicionais, quando designa para a audiência de mediação, compartilha a jurisdição com o auxiliares da justiça mediadores ou conciliadores judiciais, esse é o modo de fazer justiça inovadora, pois assim assumem juntos uma nova forma de justiça.

O juiz ao enviar o processo a um ambiente diferente de atuação, reconhece a importância dos métodos autocompositivos como a mediação e acredita-se que todos os envolvidos estarão no mesmo patamar de diálogo, no ambiente da mediação reconhece-se uma nova casa da justiça, participativa, democrática e emancipatória será uma justiça diferente, mesmo fazendo parte do Poder Judiciário. 
Os mediadores judiciais sob os princípios constitucionais e as diretrizes do CNJ utilizam-se de ferramentas adequadas de facilitador do diálogo e, com isso, empoderam as partes para encontrarem juntas a solução mais adequada e satisfatória aos conflitos.

O presente artigo tem o objetivo identificar o novo ambiente da jurisdição estatal, identificar as diferenças e refletir as mudanças que estão ocorrendo com a implementação da mediação judicial e propor uma nova jurisdição a que denomina-se de Eco-jurisdição Compartilhada ( juiz-mediadores e conciliadores) suas características na seara democrática, participativa, efetiva e humanitária da justiça, assim utiliza-se o método hipotético-dedutivo e pesquisa bibliográfica pelo referencial teórico de Luiz Alberto Warat e Boaventura de Souza Santos, bem como as experiências práticas da mediação judicial no Tribunal de Justiça do Rio Grande do Sul a seguir.

\section{A MEDIAÇÃO E O NOVO AMBIENTE DA JURISDIÇÃO COMPARTILHADA}

A jurisdição tradicional desenvolve-se no ambiente de disputa, de ganha e perde das decisões judiciais, onde as jurisdições contenciosa e voluntária tramitam-se na esfera judicial num ambiente litigioso, tendo como resultado final a falta de resolução e tampouco de tratamento dos conflitos de seus jurisdicionados.

Cabe salientar que a jurisdição tradicional está centrada na disputa entre as partes, na pretensão do autor e na resistência do réu, na formalidade do processo e em suas provas documentais, na lei e em seus reflexos materiais, estando adstrito apenas ao julgamento do pedido e na fundamentação da ação que tem como fim uma sentença.

$\mathrm{O}$ resultado procedente ou improcedente de uma sentença representa o ponto final impositivo na disputa, o que significa que, a partir do momento da sentença proferida pelo juiz e seu trânsito em julgado, a decisão que deve ser cumprida em definitivo, pois fez coisa julgada. Por outro lado, no ambiente da mediação apresenta-se a Jurisdição Compartilhada, o procedimento é diferente do julgamento do juiz, ou seja, há a outorga do juiz aos mediadores judiciais de uma responsabilidade maior, o tratamento integral do conflito.

No ambiente da mediação judicial, a casa da jurisdição muda estática e fisicamente, desta forma quando o juiz outorga aos mediadores tal encargo, significa dizer que os mediadores estão aptos ao exercício de uma capacidade multifuncional, que irão utilizar as 
técnicas, métodos de diálogos para cada caso concreto, nas sessões estipuladas a fim de tratar o conflito de forma adequada. Assim, na jurisdição compartilhada existe uma autonomia dos mediadores para exercitar um diálogo construtivo e restaurativo da comunicação entre as partes, tendo grandes chances de efetuar o tratamento do conflito de forma integral e adequada.

No ambiente da Jurisdição Compartilhada os princípios da confidencialidade, confiança, do sigilo entre os participantes é fundamental. Desenvolve-se um ambiente adequado para que transcorra o diálogo não violento, escutas escuta ativa, alternativas positivas e prospectivas dos os interesses, identificam-se as necessidades e os sentimentos dos interessados, descobrem-se a extensão do conflito, para se for possível as próprias partes encontrarem conjuntamente a melhor solução em conjunto.

Esse ambiente da Jurisdição Compartilhada está embasado no novo conceito de cidadania, aquela resgatada pelos juristas e pela Constituição, como relata Torres:

Pode contribuir extraordinariamente para o equilíbrio entre valores e princípios e para a sua concretização na era dos direitos. Sendo um dos fundamentos do Estado Democrático de Direito, nos termos do art, $1^{\circ}$, inciso II, da CF88, a cidadania harmoniza os valores da Liberdade, justiça e segurança. [...] A cidadania múltipla, que é entrecruzada, permite ainda a integração dos direitos, assim como da Liberdade, da justiça social e da solidariedade, nos espaços local, nacional e mundial, bem como virtual. [...] A cidadania participativa, com sua dimensão nitidamente processual, contribui também para integração dos direitos (2005, p. 128).

O juiz, na jurisdição tradicional, apenas se limita a pôr fim na disputa de acordo com a lei vigente. Diferente disso ocorre na Jurisdição Compartilhada, que atua num ambiente novo denominado eco-cidadania, ambiente de atuação da jurisdição contemporânea e da autocomposição.

Num ambiente de Jurisdição Compartilhada não existe poder do juiz, o poder para decisão está na mesa redonda do diálogo, do entendimento e o mediador é apenas o elo de ligação que condução do diálogo, o poder decisório está nas mãos das partes e seus interesses e necessidades que serão avaliados de forma conjunta e dialogada até encontrarem a mais adequada solução no tocante se suas possibilidades de cumprimento.

O mediador na Jurisdição Compartilhada tem a responsabilidade outorgada pelo juiz de mediar o que significa dizer que, num ambiente de cidadania, o mediador irá conduzir essa atividade meio, ou seja, utilizar todos os meios e técnicas possíveis para que as partes consigam alcançar um resultado pelo diálogo satisfatório. O mediador tem a responsabilidade de conduzir a mediação pelos princípios que lhes outorgam as leis 13.115/2015 e 13.140/2015. 
Por outro lado, a solução para o conflito em tela é direcionada às próprias partes, o mediador atua como facilitador do diálogo, sem interferências ou sugestões, assim os mediadores não entrarem em contato com o processo judicial, a fim de se conservarem neutros e imparciais as necessidades, os interesses, os sentimentos e as questões-problema das partes na mediação.

A importante Jurisdição Compartilhada exercida pelos mediadores é a comunicação oral, ativa e participativa das partes a fim de tratar a extensão total do conflito, em termos de questão sociológica, psicológica, econômica, educativa, respeitando-se os momentos de cada indivíduo, pois a mediação permite uma visão aplicada e integral do conflito, identificar a espiral de disputas de poderes na relação social, não se limitando apenas à disputa da ação judicial.

Será garantido às partes que todos os envolvidos nas sessões de mediação estarão responsáveis por manter a confidencialidade profissional. Esse requisito essencial será esclarecido em detalhes no termo de abertura $^{3}$ (mediadores, partes, observadores e supervisores), pois somente iniciará a mediação se todos tiverem a certeza e a voluntariedade de praticar, com a garantia que não poderão ser testemunha ou participar de processos futuros, em que as partes estejam envolvidas. Trata-se de um dever ético de todos que participam desta nova forma de jurisdição estatal compartilhada, a mediação de conflitos.

Outra característica da Jurisdição Compartilhada é sua atuação pelo mediador de conflitos, o que representa a atuação de uma justiça democrática, em que todo e qualquer cidadão poderá exercer a escolha de método de resolução de seu conflito, de forma voluntária e participativa, envolvendo-se num processo de emancipação do Estado e de seu monopólio estatal. Aos contrário do juiz que sua sentença faz lei entre as partes e a mediação conta com mediadores judiciais que são auxiliares da Justiça Estatal a capacitados para trabalhar o diálogo ativo e responsável, a fim de que as partes efetuem de forma espontânea e efetiva o convencionado, sem a necessidade de executar ou propor nova ação.

\footnotetext{
${ }^{3} \mathrm{O}$ termo de abertura é o nome dado ao procedimento inicial da mediação de conflito, que na prática esclarece aos mediandos como será realizada a mediação, o que é mediação, quais são suas atribuições de cada um, o que os mediadores esperam dos mediandos, a obrigação da oralidade, imparcialidade, sigilo, autonomia da vontade das partes, as exceções quando a confidencialidade será quebrada, pois se houver qualquer notícia-crime, os mediadores terão a obrigação de encerrar a mediação e enviar o processo para o juiz, visto que matéria criminal a mediação judicial não possui jurisdição para mediar. Porém cabe destacar que o objeto da mediação não precisa ficar adistrito ao proposto na demanda inicial, como ocorre no processo judicial, por outro lado, pode ser simplificado ou ampliado, visto que a autocomposição permite tal alternativa, incluindo ou excluindo partes e objetos (AZEVEDO, 2013, p. 54).
} 
Para tanto, passamos a analisar como a mediação judicial e a nova forma de jurisdição compartilhada, efetua-se a nova casa da justiça consensual que começou a vigorar no Poder Judiciário após a promulgação do CPC/2015, em todos os graus de jurisdição a fim de surtir os efeitos de consenso e entendimento com efetividade e de forma humanizada.

3. A casa da justiça do século XXI: a Eco-jurisdição Compartilhada do consenso e do entendimento

A mediação de conflito regulada pelas Leis $n^{\circ} 13.140 / 2015$ e $n^{\circ} 13.105 / 2015$ iniciou a oportunidade de implementação no Poder Judiciário de um novo ambiente para tratamento de conflito, um ambiente neutro, compartilhado que é propício para o diálogo, a escuta ativa e a busca da harmonia das relações interpessoais, da transparência e de respeito pelo consenso, pela cooperação alcançada, em que os jurisdicionados possam expressar seus sentimentos e seus interesses e necessidades de forma confidencial.

A mudança do espaço de tratamento de conflitos na mediação judicial, instalou-se o ambiente propício para uma Jurisdição Compartilhada, a eco-jurisdição é a nova casa da justiça do século XXI (eco = casa, ambiente, e jurisdição = tutela do Estado para tratamento adequado do conflito). Consequentemente, a mediação e a conciliação traduzem a Eco-jurisdição Compartilhada, pois o juiz compartilha a nova casa da justiça com os novos auxiliares da justiça (mediadores e conciliadores), a fim de permitir, por meio do diálogo e da cooperação da mediação de conflito, transformar o ambiente da justiça.

A mediação judicial, ao ser normatizada pelas Leis $\mathrm{n}^{\circ} 13.140$ e $\mathrm{n}^{\mathrm{o}} 13.105 / 2015$, tem como escopo reconstruir e inovar a casa da justiça, dar oportunidade de manter a segurança jurídica e atualizar o novo domicílio para tratamento de conflito com efetividade e humanização, de forma diferente, singular, única, tendo um paradigma autônomo, voluntário e participativo dos sujeitos, razão pela qual se passa a denominar eco-jurisdição.

Importante salientar que a mediação de conflito é o novo domicílio de tratamento de conflito, assim como conceitua Venosa "A atividade jurídica e social da pessoa manifesta-se no tempo e no espaço definido. O lugar em que a ação jurídica da pessoa se exerce de modo contínuo e permanente é o seu domicílio.” (p.199) Portanto, os mediandos elegem a mediação para tratar o conflito estão optando por uma jurisdição compartilhada, pois a mediação é a novo domicílio do tratamento do conflito na Justiça Estatal , o local de morar com ânimus definitivo e não temporário, assim constitui-se o objetivo da jurisdição contemporânea pelo consenso. 
A eco-jurisdição é o nome que designa a nova casa da Jurisdição Compartilhada na esfera judicial, com paradigmas contemporâneos, sem as colunas jônicas, dóricas e coríntias da tradição de justiça (que representam o poder dos templos gregos), mas, pelo contrário, a casa contemporânea jurisdicional é representada pela nova arquitetura da justiça de formas retas e cubos com mesas redondas das casas modernas, para facilitar o diálogo próximo e informal dos mediandos, sem hierarquia ou discriminação, onde reside a eco-cidadania, a igualdade, a confidencialidade e a cooperação dos seus agentes.

Assim, essa nova jurisdição, a eco-jurisdição compartilhada pode ser entendida como as casas contemporâneas de linhas retas e de telhado quadrado, telhado embutido para representar igualdade entre os cidadãos, pois não existe hierarquia entre as partes na mediação. Nas casas de formato piramidal e pode ser representada pela jurisdição tradicional onde os mais velhos tinham o direito de ficar no andar de cima, no topo, ou nos quartos com sacadas para demonstrar hierarquia e poder previamente instituído, para supervisionar.

As novas casas da jurisdição compartilhada ( eco-jurisdição) possuem muros de vidros, para refletir a transparência, a participação democrática de todos, mesmo que confidencial, sigilosa e privada. A transparência estará no acordo que as partes construírem de forma voluntária e dialogada, para a construção de um diálogo co-construído e harmônico. A cor da casa contemporânea é branca para representar a paz que todos esperam encontrar no seu interior e na continuidade do cumprimento do acordo. No centro, há uma mesa redonda para o diálogo como foco principal e não a sentença impositiva.

A nova casa da jurisdição compartilhada ( eco-jurisdição) pode estar repleta de novas tecnologia, mas traduz o bem-estar de que os indivíduos necessitam para reestabelecer o equilíbrio em suas relações, os recantos acolhedores de comunicação, diálogo e compreensão de si e do outro, com o escopo de proporcionar ao indivíduo ter vez, voz e poder compartilhar suas necessidades e seus interesses diferentes, mas em igualdade de condições e respeito, e decidir o melhor caminho para seus conflitos comtemporâneos.

No entender de Branco, a arquitetura da justiça deve ter,

(...) a dimensão de garantia do acesso ao direito e à justiça, entendida como função de uma eficaz e efetiva proteção jurisdicional, conexionada com a igualdade de armas, deve passar, também - e é esta a dimensão que pretendo trazer ao foro - pela qualidade dos seus espaços, dos seus edifícios, da forma como permitem aos seus utilizadores exercitarem a sua cidadania em espaços dignos (que não têm de ser construídos de raiz, mas que devem ser adaptados de forma adequada, de modo a prever valências e acessibilidades, assegurando 
a funcionalidade do edifício e garantindo condições de conforto aos profissionais e aos utentes), que legitimam, por meio dessa qualidade e dignidade, a própria justiça (2015, p. 120).

Ainda, a nova casa da Jurisdição Compartilhada está amparada nos princípios da neutralidade e da imparcialidade dos mediadores, da informalidade e da oralidade na exposição dos interesses de cada parte, na autonomia da vontade e na confidencialidade que é garantida as partes, bem como a possibilidade transformar os indivíduos em entes multiplicadores do bem social, não no modelo utópico (do paz e amor dos anos 60), mas no modelo adequado para tratamento dos anos de 2018 (autocomposição-consenso-efetividade-emancipação), transformando os mediandos em agentes propulsores do diálogo positivo e da construção coletiva para o entendimento.

A prática da mediação judicial, realizada com qualidade e profissionalismo, conduzirá os jurisdicionados a: a) sentirem que o espaço de fazer justiça está diferente, oral e informalmente igualitário, uma esfera diferente; b) os indivíduos exercitando o poder de decidir por outra esfera, coparticipativa, corresponsável e colaborativa conduzem a um movimento de ressonância no mundo jurídico, ou seja, que se propaga para todas as esferas e graus de jurisdição, um movimento constante de autoaprendizagem pelo diálogo, de co-construção de estruturas fortificadas para o empoderamento de um acordo satisfatório para as partes.

No novo mundo da jurisdição contemporânea compartilhada (eco-jurisdição), deve ser compreendido como a conexão de dois fatores fundamentais, teóricos contemporâneos como a "Ecologia de Saberes" (SANTOS, 2014) mais a "Eco- cidadania" (WARAT, 2004). Assim, a Jurisdição Compartilhada resulta da justiça multiopcional, fundada no conhecimento do outro e no exercício da cidadania, pois, assim, se espera de todos os cidadãos, no exercício de uma justiça democrática, busquem efetuar a Jurisdição Compartilhada pela mediação, por entenderem ser o melhor caminho a seguir.

A compreensão do mundo e como conviver é fundamental como expõe Santos,

A ciência moderna legou-nos um conhecimento funcional do mundo que alargou-extraordinariamente as nossas perspectivas de sobrevivência. Hoje não se trata tanto de sobreviver como de saber viver. Para isso é necessária uma outra forma de conhecimento, um conhecimento compreensivo e íntimo que não nos separe e antes nos uma pessoalmente ao que estudamos." (2010, p. 53-54). 
Nessa linha de raciocínio a cidadania está intimamente ligada a autonomia e a continuidade da vida, por isso para Warat, afirma,

Seria uma visão do ecológico que apostaria nos caminhos da autonomia como resposta a seu problema central: a continuidade da vida. A cidadania sustentável (enquanto direito e gênero) como limite a um poder que se cuida a si mesmo, descuidando a vida (WARAT, 1994, p. 104).

Warat aponta três objetivos fundamentais para reaprendermos o mundo,

(....) como uma fórmula que possa nos servir para reaprendermos o mundo através de três objetos de análise: a ecologia, a cidadania e o desejo. Três pontos de vista que, funcionando integrados (como 'eco-cidadania'), permitirão recompor os objetivos do conjunto dos movimentos sociais (como redes) nas condições irreversíveis da transmodernidade (o homem nunca voltará a ser o que era na modernidade). (WARAT, 1994, p. 98).

Cabe destacar que a definição de "Ecologia de Saberes" de Santos é "um modo de pensar a sociedade e de habitar o mundo, retratando uma imensa riqueza de experiência que não podem ser desperdiçadas. Através de múltiplos encontros, diálogos e traduções, emerge um processo continuado de aprendizagem.” (SANTOS, 2014, p. 107).

No mesmo sentido, a presença aprendizagem efetiva do eco-cidadania de Warat,

Que representa uma mudança ética, estética, política e filosófica profunda. Seria a possibilidade de criar um novo eixo emancipatório (para autonomia individual e coletiva) que possa ocupar, na tarefa de recompor permanente a sociedade, o lugar dos antigos e já trivializados valores emancipatórios (2004, p. 407).

Assim, destaca Santos que o conhecimento também reside no senso comum e por isso afirma:

Ao contrário, a ciência pós-moderna sabe que nenhuma forma de conhecimento é, em si mesma, racional; só a configuração de todas elas é racional. Tenta, pois, dialogar com outras formas de conhecimento deixandose penetrar por elas. A mais importante de todas é o conhecimento do senso comum, o conhecimento vulgar e prático com que no quotidiano orientamos as nossas ações e damos sentido à nossa vida. A ciência moderna construiu-se contra o senso comum que considerou superficial, ilusório e falso. A ciência pós-moderna procura reabilitar o senso comum por reconhecer nesta forma de conhecimento algumas virtualidades para enriquecer a nossa relação com o mundo. É certo que o conhecimento do senso comum tende a ser um conhecimento mistificado e mistificador mas, apesar disso e apesar de ser conservador, tem uma dimensão utópica e libertadora que pode ser ampliada através do diálogo com o conhecimento científico. Essa dimensão aflora em 
algumas das características do conhecimento do senso comum. (SANTOS, 1988, p.70)

Portanto, o ambiente da nova Jurisdição Compartilhada torna-se a eco-jurisdição estatal compartilhada e se transforma na co-construção da nova justiça, informal, ética, estética, oral, confidencial, acessível, dialogada, voluntária, na qual os sentimentos, as necessidades e os interesses das partes são prioridades.

Então, conclui-se que a eco-jurisdição congrega o diálogo contínuo e o tratamento do conflito, um projeto positivo para o futuro dos participantes, em que será trabalhada não apenas a disputa posta em causa, mas a cultura do cooperativismo, da reconstrução e do tratamento do passado, bem como as necessidades de as partes estarem conscientes das decisões tomadas no presente para o seu cumprimento efetivo.

\section{CONCLUSÕES}

$\mathrm{O}$ acesso à justiça é um direito básico de todos os cidadãos garantidos constitucionalmente no art. $5^{\circ}$ da $\mathrm{CF} / 88$, porém esse direito foi ampliado com a implementação das Leis no 13.105 e 13.140/2015, pois a função do Estado é promover, sempre que possível, a solução consensual de conflitos de forma adequada e eficaz. Nessa seara foi instaurado os meios autocompositivos na esfera judicial de forma efetiva que veio a modificar a jurisdição tradicional existente. Com a premissa que antes da litigiosidade deve-se dar abertura os meios autocompositivos, altera-se a jurisdição proporcionando aos jurisdicionados uma jurisdição compartilhada quando o juiz envia o processo aos mediadores ou conciliadores a fim de efetivar o tratamento do conflito em outra esfera.

Com o objetivo de demostrar que na esfera judicial pode existir três tipos de tipos de jurisdição a contenciosa onde vigora a litigiosidade, a voluntária onde busca-se ajuste de um direito a ser efetivado e a compartilhada onde o juiz outorga aos mediadores uma jurisdição do diálogo, do consenso e do entendimento.

Neste ambiente a pesquisa identifica que na mediação realiza-se em um novo modelo de jurisdição judicial e, por isso, a prestação jurisdicional do Estado-Juiz sofreu alterações, que denominamos de Jurisdição Compartilhada, num ambiente inovador da nova casa da jurisdição, a Eco-jurisdição contemporânea, saindo do modelo de jurisdição tradicional denominada 
voluntária e contenciosa para uma nova jurisdição compartilhada, participativa, humanizada e dialogada.

Sabe-se que a atividade jurisdicional é aberta e complexa, pois o juiz em suas atribuições jurisdicionais, quando designa para a audiência de mediação, compartilha a jurisdição com o auxiliares da justiça chamado mediador judicial, esse é o modo de fazer justiça inovadora, um trabalho de equipe em prol da cidadania e da justiça participativa, pois assim assumem juntos uma nova forma de justiça.

O juiz ao enviar o processo a um ambiente diferente de atuação, reconhece a importância dos métodos autocompositivos como a mediação e acredita-se que todos os envolvidos estarão no mesmo patamar de diálogo, no ambiente da mediação reconhece-se uma nova casa da justiça, participativa, democrática e emancipatória será uma justiça diferente, mesmo fazendo parte do Poder Judiciário.

Nesse novo ambiente emancipatório e democrático da jurisdição ocorre o diálogo dos protagonistas que são os verdadeiros agentes da construção do diálogo, da mediação. O foro inovador da esfera confidencial da justiça proporciona um ambiente de empatia e de confiança entre mediadores e partes. Consequentemente, proporciona um meio ambiente (eco) propício para que a jurisdição do diálogo e da cooperação que renasça por meio do acordo construtivo, com satisfações mútuas dos envolvidos e sucesso na efetivação do seu cumprimento, visto que não foi imposto pelo juiz, apenas solicitada a homologação do interesse construído pelas partes, em conjunto e com mútuo consentimento.

Conclui-se que os cidadãos, ao optarem pela mediação de conflito judicial terão a certeza de que, na prática da jurisdição estatal compartilhada, terão um tratamento adequado de seu conflito. No ambiente de eco-jurisdição as mediações e suas sessões serão conduzidas com liberdade de falar e diálogo, inclusive, em todas as situações, os documentos, as informações e as propostas expostas durante a mediação, serão mantidos sob o necessário sigilo até as partes encontrarem juntas o consenso ou a melhor opção para o caso de forma satisfatória.

\section{Referências}

AZEVEDO, André Gomma de (Org.). Manual de Mediação Judicial. Brasília - DF: Ministério da Justiça e Programa das Nações Unidas Para O Desenvolvimento - PNUD, 2012.

SANTOS, Boaventura de Souza. Um Discurso sobre as ciências na transição para a ciência pósmoderna. In: Estudos Avançados. São Paulo. V. 2, n², Maio-agosto, 1988. p. 47-71. Disponível em : http://www.scielo.br/pdf/ea/v2n2/v2n2a07.pdf . Acesso em 03.09.2018. 
Democratizar a Democracia: Os caminhos da democracia participativa. Porto: Afrontamento, 2010.

Para uma revolução democrática da justiça. 3. ed. São Paulo: Cortez, 2014.

TORRES, Jasson Ayres. O Acesso à Justiça e soluções alternativas. Porto Alegre: Livraria do Advogado, 2005.

VENOSA, Silvio de Salvo. Direito civil: parte geral, 8 v. São Paulo: Atlas, 2008.

WARAT, Luis Alberto. Eco-cidadania e Direito: Alguns aspectos da Modernidade, sua decadência e transformação. 1994. Disponível em: https://periodicos.ufsc.br/index.php/sequencia/issue/view/1516/showToc. Acesso em 05. set. 2018.

WARAT, Luís Alberto et al. Surfando na pororoca: ofício do mediador. Florianópolis - SC: Fundação Boiteux, 2004.

WARAT, Luís Alberto. A Cidadania E Direitos Humanos Da Qualidade Total. 2004b. Disponível em: <http://emeron.tjro.jus.br/images/biblioteca/revistas/revista-emeron-122004.pdf >. Acesso em: 15 dez. 2016.

WARAT, Luís Alberto. Do Paradigma Normativista ao Paradigma da Razão Sensível. In: MELEU, Marcelino; GAGLIETTI, Mauro; COSTA, Thaise Nara Graziottin (Org.). Temas Emergentes No Direito. Passo Fundo, RS: Editora IMED, 2008, p. 13-56. 